\title{
What are the merits of endogenising land-use change dynamics into model-based climate adaptation planning?
}

\author{
Bramka Arga Jafino ${ }^{1}$, Marjolijn Haasnoot ${ }^{1,2}$, and Jan H. Kwakkel ${ }^{1}$ \\ ${ }^{1}$ Delft University of Technology, Delft, The Netherlands \\ ${ }^{2}$ Deltares, Delft, The Netherlands
}

\begin{abstract}
Integrated assessment models often treat land-use change as an external driving force. In reality, land-use is influenced by environmental conditions. This paper explores the merits of endogenising land-use change, i.e. making land-use change an internal dynamic process in models used for supporting climate adaptation planning. For this purpose, we extend the Waas environmental impact assessment model, a hypothetical case study previously used for exploring new model-based climate adaptation approaches. We use a utility-based land-use change model for endogenising the land-use dynamics, evaluate its implications, and identify the conditions under which endogenising land-use change becomes important. We find that endogenising land-use dynamics changes the performance of the policies, allows for assessing policies that target land-use, and widens the outcomes of interest that can be considered. The relevance of endogenising land-use dynamics depends on (i) the expected degree of future climate change, (ii) the society's sensitivity to climate events, and (iii) the types of policies that decision makers want to evaluate. Ignoring the interaction between the environment and the society (in this case the land-use) can result in both under- and overestimation of the impacts of adaptation and might limit the adaptation options that are considered.
\end{abstract}

\section{Keywords}

Land-use; adaptation planning; integrated assessment model

\section{Code Availability}

The loosely-coupled Waas model was developed by coupling an environmental impact assessment model (EIAM) and a land-use change model (LUCM). The EIAM was developed using the high level programming language Python 2.7 and the open spatio-temporal model software PCRaster 4.0.2 (http://pcraster.geo.uu.nl/). The LUCM was developed using the Land Use Scanner model (https://spinlab.vu.nl/research/spatial-analysismodelling/land-use-scanner-model/). The model can be made available upon contact with the authors. The data from the simulation results and the scripts used for the analysis can be accessed at https://github.com/bramkaarga/waas landuse couple.

\footnotetext{
Correspondence:

Contact B.A. Jafino at b.a.jafino@tudelft.nl

\section{Cite this article as:}

Jafino, B.A.; Haasnoot, M. \& Kwakkel, J.H.

What are the merits of endogenising land-use change dynamics into a model-based climate adaptation planning?

Socio-Environmental Systems Modelling, vol. 1, 16126, 2019, doi:10.18174/sesmo.2019a16126

This work is licensed under a Creative Commons Attribution-NonCommercial 4.0

International License.

\section{Socio-Environmental Systems Modelling}

An Open-Access Scholarly Journal 


\section{Introduction}

Decision makers in climate adaptation planning face uncertainties about the future context within which adaptation measures need to be implemented (Dessai \& van der Sluijs, 2007). Nevertheless, decisions still have to be made, or at least planned in advance, as failing to do so may result in adverse impacts (Füssel, 2007) and may limit options (Haasnoot et al., 2012). Embracing this challenge means changing the adaptation planning approach from developing static plans that assume a well-characterised future to designing dynamic plans that perform good enough under deep uncertainties (Maier et al., 2016; Walker et al., 2013). The central idea behind dynamic planning is that the plan should allow for flexible adjustment over time in response to new information that decision makers will obtain in the future. One way to develop dynamic plans is to evaluate alternative sequences of decisions (adaptation pathways) in order to identify short-term actions and long-term options for adaptation. This way of dynamic planning is exemplified by the Dynamic Adaptive Policy Pathways approach (Haasnoot et al, 2013). To support decision makers in developing dynamic plans, Haasnoot et al. (2014) suggest the use of fast integrated assessment models to design adaptation pathways.

Integrated assessment models (IAMs) combine the knowledge of a broad range of disciplines in order to provide added values for policy support and decision-making processes (Van Delden et al., 2011). The transdisciplinary nature of IAMs has increased their popularity as a decision support tool for climate adaptation planning (Chambwera et al., 2014; Patt et al., 2010). IAMs have been used for decision support at various scales, ranging from city scale (Chang et al., 2008; Hall et al., 2010), province scale (Carmona et al., 2013; Qureshi et al., 2013), national scale (Gao \& Bryan, 2017; Oxley et al., 2013), regional scale (Cofala et al., 2010), and global scale (Rotmans et al., 1990; Schwanitz, 2013).

The shift to designing dynamic plans requires a modelling approach that considers a large ensemble of plausible futures (Lempert, 2003). This necessitates a model that has a limited simulation runtime. There is no one clearcut time threshold to indicate whether a model is sufficiently fast. Rather, it depends on one's computational capacity and the time availability for the analysis. The model should be fast enough to run a large number of scenarios (in the order of thousands to hundreds of thousands of simulation runs).

Such models can be developed by simplifying detailed models while retaining the ability to sufficiently mimic the system. To realise this, Haasnoot et al. (2014) suggest the use of theory informed metamodeling, resulting in fast integrated assessment meta-models (IAMMs). The aim of IAMMs is to approximate the behaviour of a more detailed model within a reasonably shorter runtime. IAMMs can be constructed purely based on statistical inferences between the variables in the complex model (Barton, 1998), or based on the combination of the statistics and the representation of the processes within the system (Davis \& Bigelow, 2003). Given the same set of inputs, the IAMM is expected to yield outputs that are similar to the complex model (Hamilton et al., 2015).

Uncertainties in climate adaptation planning may arise from natural, socioeconomic, and technological systems (Haasnoot et al., 2009; Moss et al., 2010; Refsgaard et al., 2007). Recent studies suggest that in the context of climate adaptation planning, the impacts of socioeconomic uncertainties may be more profound than climate change uncertainties (Harrison et al., 2016). For instance, Audsley et al. (2015) show that population growth and commodity import dynamics have a bigger impact on agriculture intensification and deforestation, compared to uncertainties about precipitation and temperature. Holman et al. (2016) demonstrate that a higher variability in the urban, coastal, land-use, water, and biodiversity impact indicators can be attributed to socioeconomic scenarios rather than to uncertain temperature dynamics. Fant et al. (2016) investigate the magnitude of population exposed to water stress while isolating climatic and socioeconomic uncertainties independently, and find that the socioeconomic drivers yield higher variance in outcomes. In fact, a part of climate change adaptation is the autonomous choices by the people to change their social and economic livelihood, such as by migrating to areas that are less exposed to climate impacts (Hauer, 2017). Such autonomous adaptation is not comprehensively addressed in climate adaptation studies, or is treated as an uncertainty that is exogenous to the analysis. This practice may undermine human adaptations to climate change and may result in a flawed analysis which overestimates negative impacts (Cass, 2018). 
In spatially explicit IAMs, socioeconomic uncertainties are often manifested in the form of several alternative future land-use maps (Swetnam et al., 2011). The land-use maps, however, are often treated as a static exogenous input to the IAMs (Wada et al., 2017). They are created by other independent means and then used as input to the IAM (Brown et al., 2004; Taylor et al., 2012). In reality, land-use dynamics and climate change are part of an inseparable socio-environmental system. There are bidirectional interactions between them (Filatova et al., 2013). Land-use decisions are influenced by the behaviour of the natural system (Lambin \& Meyfroidt, 2010; Wagner \& Waske, 2016), while the performance of the natural system is affected by land-use decisions (Abd El-Kawy et al., 2011; Laliberté et al., 2010; Stonestrom et al., 2009). To this end, a recent study by Wagner et al. (2016) has demonstrated a new approach by dynamically adding new land-use maps to a hydrologic model at multiple points of time in the simulation. The standard static land-use maps approach has proven to underestimate the hydrological impacts if future land-use changes follow a non-linear path (Wagner et al., 2017). In spite of the innovativeness, the interaction between the dimensions in this work is still unidirectional: from the land-use to the environment.

This paper aims to identify the merits of making the land-use change dynamics an internal process in a spatially explicit integrated assessment model used for supporting climate adaptation planning. What are the implications of endogenising land-use change dynamics in simulation models used for supporting adaptation planning? Under what circumstances do these implications materialise? For answering these questions, we utilise a flood risk IAMM of the stylised Waas case study (Haasnoot et al., 2012). We make the land-use change endogenous by extending the environmental-based IAMM with an independent land-use change model. We apply pairwise comparisons between simulation runs where land-use dynamics are endogenised and are kept exogenous, and observe how the policy performance indicators are affected. We also explore the potential of having policies that target the land-use dimension in addition to the original physical-based policies. We extend the performance indicators being observed by having disaggregated, actor-based policy performance indicators (e.g., welfare/utility of actor groups, flood risk for each dike ring) in addition to the aggregated policy performance indicators (e.g., total welfare, total rice production, total flood risk) that are prominent in modelbased climate adaptation studies.

The remainder of the paper is structured as follows. In Section 2, we outline the building blocks of the model that comprise the environmental impact assessment model, the land-use change model, and the coupling mechanism between these two models. In Section 3, we introduce the case study and the experiments design. In Section 4, we report the results of the experiments, and in Section 5, we discuss the key findings from the experiments. Last but not least, the conclusions are presented in Section 6 .

\section{Loosely-coupled integrated assessment and land-use change model}

\subsection{The Environmental Impact Assessment Model}

The natural system in this study is encapsulated in an environmental impact assessment model. The main aim of this model is to translate climatic pressures into socioeconomic impacts. The model is built upon the integrated assessment meta-model (IAMM) paradigm. The IAMM follows the theory-motivated metamodel approach (Davis \& Bigelow, 2003). In this approach, the IAMM is constructed partly from statistical inferences from more complex models, and partly from the physical processes of the system. The Drivers-Pressures-StateImpacts-Responses (DPSIR) concept (Niemeijer \& de Groot, 2008) underlies the cause-effect relations. The approach is applied in the context of flood risk management in the presence of climate change (Haasnoot et al., 2012).

As an example of the DPSIR framework, uncertainties about future climate change and socioeconomic development (drivers) are translated into maximum annual river discharge and future land-use claims (pressures), which in turn affect the probability of flood event occurrence and the land-use pattern (state). If flood events occur, the damage (impact) is incurred based on the physical properties and the land-use function of the flooded area. Decision makers then respond to these risks by implementing policies (responses) that may reduce the probability (affecting the state) or the consequences (affecting the impacts) of the flood risks. In this paper, an iterative process of the DPSIR concept is followed: responses are predetermined and implemented in advance so that their efficacy can be evaluated ex-ante. The implementation of the DPSIR concept into the IAMM is schematised in the blue box in Figure $1 \mathrm{a}$. 
(a)

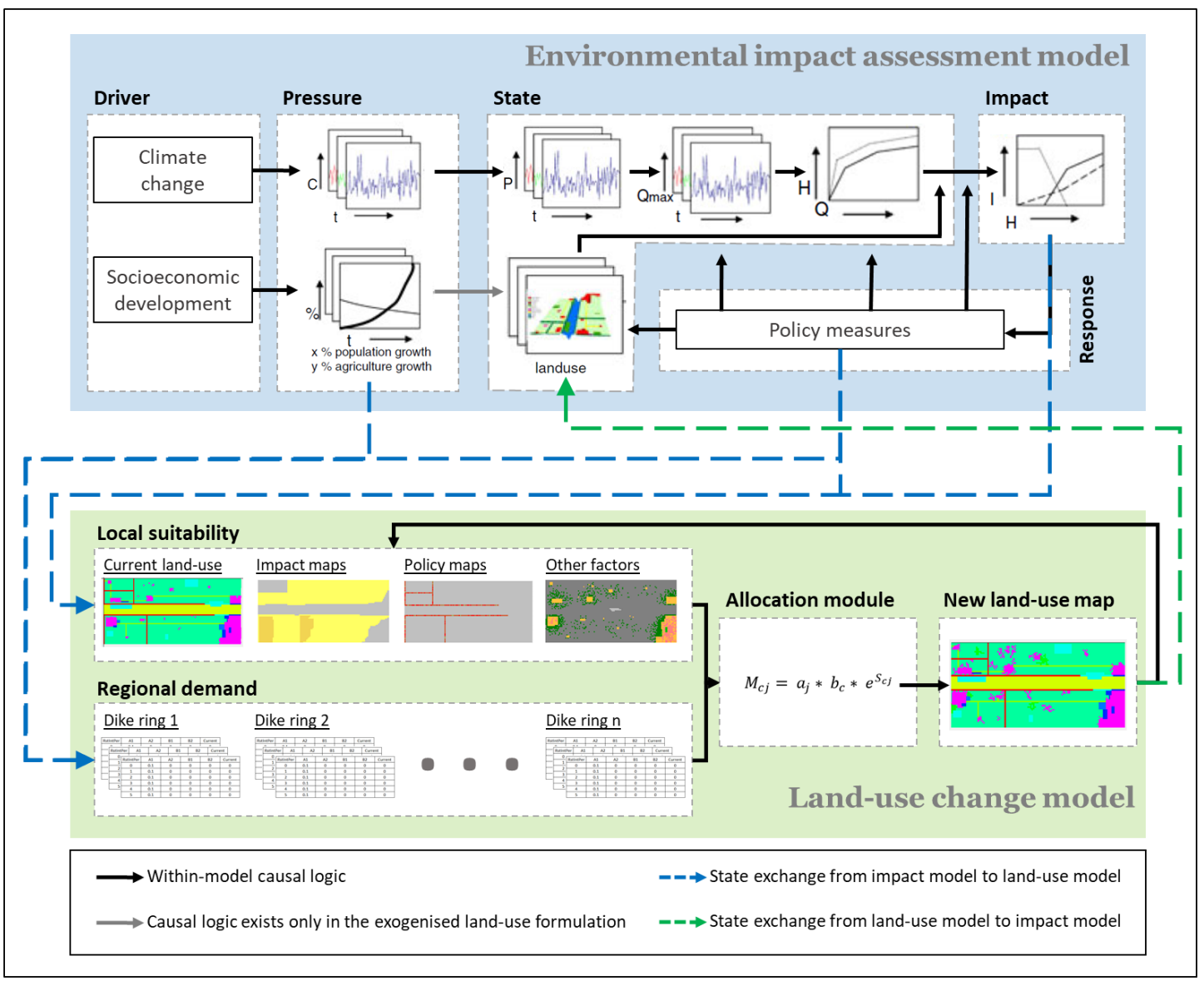

(b)

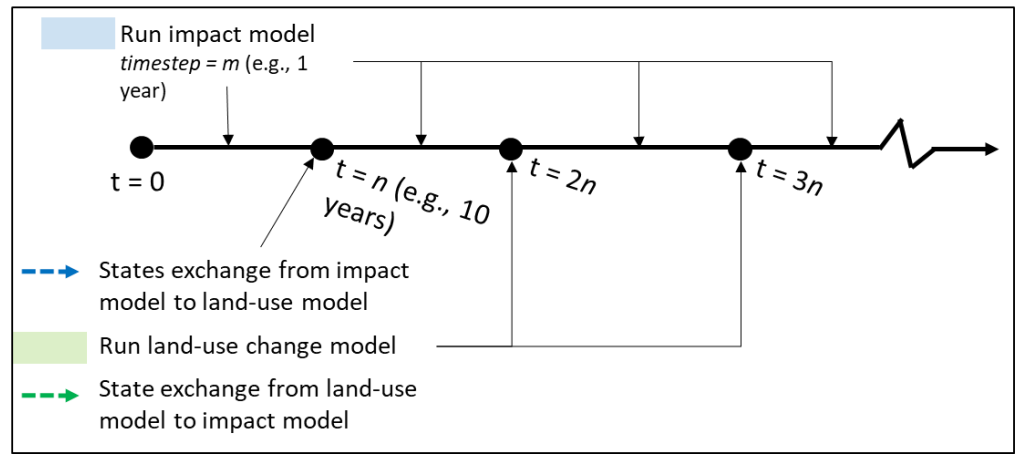

Figure 1: Conceptualisation of the integrated assessment model; (a) cause-effect relationships within and between the Environmental Impact Assessment Model (blue box, adapted from Haasnoot et al. (2012)) and the land-use change model (green box); (b) the states and time integration scheme for models coupling, the colored boxes and arrows refer to modules and relationships in (a).

\subsection{The land-use change model}

Land-use modelling approaches can be classified into two categories: the inductive, data-driven approach, and the deductive, theory-induced approach (Overmars et al., 2007b). The two approaches differ in how local suitability, i.e. the attractiveness of a given parcel on a grid to each land-use class, is defined. Given a set of spatially explicit variables, the inductive approach employs statistical techniques to identify the variables that are significant in explaining land-use changes (see e.g. Lesschen et al., 2005; Serneels \& Lambin, 2001). Conversely, the deductive approach starts from understanding the underlying decision-making processes for 
each land-use class, then combines this information with the spatially explicit variables (see e.g. Diogo et al., 2015; Van Delden et al., 2010).

The inductive approach is more widely used in economics-based land-use modelling due to its better performance in reproducing historical land-use pattern (Overmars et al., 2007a). This approach, however, has a conceptual drawback. Due to the nature of statistical techniques, this approach fails to capture the importance of variables that have historically been constant. For instance, if the data shows no significant changes in precipitation patterns, then the importance of this variable would be underestimated by the inductive approach, while in reality this variable may play a significant role in the agriculture sector's decision making. This makes the inductive approach less suitable for model-based support for climate adaptation, in which the main objective is to explore the performance of policies under uncertain changing conditions (Dessai et al., 2009). Therefore, in this paper we adopt the deductive approach.

The local suitability of the land-use classes is defined based on a utility framework (Koomen et al., 2015). Here, the local suitability of a parcel for a certain land-use class is calculated based on the combined economic and social utility of that parcel. This approach establishes a behavioural logic to the model and facilitates a forthright interpretation of the decision-making processes.

Besides the local suitability module, the land-use change model in this study has two other modules: the regional demand module and the allocation module (Koomen et al., 2011). The regional demand module contains information on the projections of the total future demand for each land-use class, distributed over the specified regions. The projections and the current existing area of a land-use class become the future land claim of that land-use class, which in turn will be allocated to the individual parcels by the allocation module. The allocation module uses a doubly-constrained logit model that combines the land claims and the spatially explicit local suitability information (Hilferink \& Rietveld, 1999). The relations among the local suitability, regional demand, and allocation modules are exhibited within the green box in Figure 1a.

\subsection{Loose and bidirectional coupling of the model}

We integrate the environmental impact assessment model and the land-use change model in a loosely-coupled and bidirectional manner (Antle et al., 2001). In this approach, the coupling is done between two or more standalone submodels that can still be run independently despite the presence of the other models. The state variables of one submodel become the input vector for the other submodels. The bidirectional nature implies that state exchange happens in two directions.

The loose and bidirectional coupling of the two models involves states and time integrations as schematised in Figure 1b. First, the environmental impact assessment model is run for $m$ time step. Every $n$ time step, where $n$ $\geq m$, several states from the environmental impact assessment model are fed into the local suitability and the regional demand modules within the land-use change model (the blue dashed lines in Figure 1a). The allocation module is then executed and the resulting new land-use map is fed back to the environmental impact assessment model. The impact assessment model then continues running and the same states exchange procedure is carried out every $n$ time steps.

Three types of state information are transferred between the models: the impact maps, the socioeconomic pressures, and the land-use maps. The impact maps become one of the determinants of the local suitability. The socioeconomic pressures are translated into future land area claims of each land-use class in the regional demand module, distributed across the regions in the system. This is the key difference between the endogenised and the exogenised land-use dynamics model formulation. In the exogenised one, new land-use maps are created top-down in advance without taking into account the climatic impacts. In the endogenised case, new land-use maps emerge from bottom-up decisions that consider experienced climatic impacts.

There are two additional types of policies that could be implemented when land-use change dynamics are endogenised: the region-level and the grid-level zoning policies. The former influences the regional demand module while the latter adds additional policy maps to the local suitability module (see the green box in Figure 1a). An example of the first type could be the restriction of further industry development in disaster prone regions. Applying this policy means subtracting the industrial land claim in certain regions to zero and adding it to the other regions in the regional demand module. An example of the second type could be the protection of 
nature area from urban development. This policy could be applied by adding an additional policy map that represents the closeness of each parcel to the nature area. The closer a parcel to any existing nature area, the less suitable it is for future residential area.

\section{Application: The extended Waas case}

\subsection{Background}

We use the hypothetical 'Waas' case, a climate adaptation flood risk case study that schematises the Waal, a river reach in the Netherlands part of the Rhine Delta (Haasnoot et al., 2012). The Waas case is an Environmental Impact Assessment Model that simplifies the land-use representation of the Waal river, for instance by having fewer dike rings. However, the modelled physical processes are highly representative. The flooding mechanisms are derived from other validated models previously used for studies on the Waal river. This theoretical case study has been frequently used as a lab experiment to test the consequences of new approaches for modelbased adaptation planning (e.g., Buurman \& Babovic, 2016; Kwakkel et al., 2015, 2016; Manocha \& Babovic, 2018; McPhail et al., 2018).

Figure 2 shows the spatial representation of the model. There are five dike rings protected by embankments alongside the river. Agricultural is the dominant land-use function. A large city exists on the higher elevated ground in the southeast part of the delta. The model encompasses an area of approximately $300 \mathrm{~km}^{2}$, divided into parcels $200 \mathrm{~m} \times 200 \mathrm{~m}$ in size.

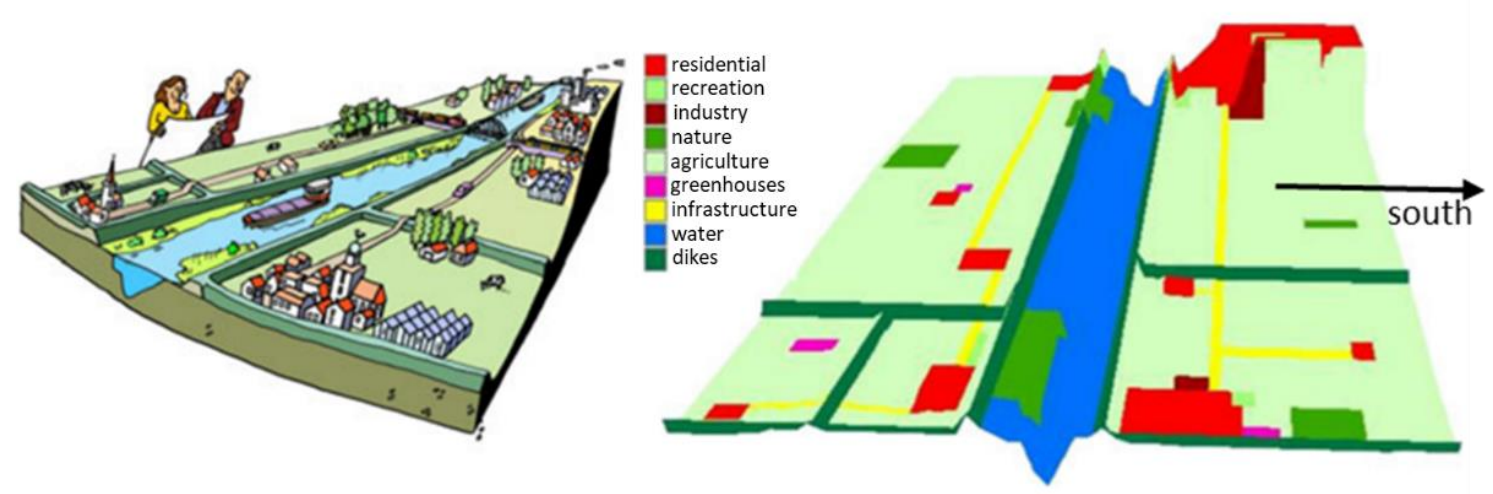

Figure 2: Spatial visualisation of the Waas Environmental Impact Assessment Model (Haasnoot et al., 2012).

The Environmental Impact Assessment Model comprises cause-effect relations, depicted in the blue box in Figure 1a. The climate realisations $(C)$ define the precipitation rate $(P)$, in turn translated into the maximum annual discharge of the river $\left(Q_{\max }\right)$. The discharge is translated into maximum water levels $(H)$ using discharge rating curves. The water levels are compared with the dike heights. The difference between the water levels and the dike height determines the probability of dike failures due to overtopping, breaching, and/or piping. Dike failures cause inundation of the floodplain. The water depth on the floodplain is calculated based on the intersection of the water level of the river and the elevation of the area. As we only consider large-scale annual flood events, smaller pluvial flood events caused by rainfall and surface runoff are not accounted in the model. Damages from flood events $(I)$ are calculated based on the water depth and land-use damage relations functions. The model is developed by using the PCRaster library, a Python-based environment to simulate process-based spatiotemporal models (Karssenberg et al., 2010; Schmitz et al., 2013; Wesselung et al., 1996).

Focusing on flood risks, we evaluate the following outcomes that were used in the original Waas case study: the total flood damage ( $\mathrm{M}$ euro), the area of residential sector flooded $\left(\mathrm{km}^{2}\right)$, and the agricultural flood damage ( $\mathrm{M}$ euro). Flood damage on each cell is calculated based on the water level, the elevation, and the dominant landuse class on that cell. The shape of the damage curves is derived from the Standard Dutch Damage and Casualty Model (Kok, 2005). The model is run with an annual time step for a planning horizon of 100 years. Therefore, the values of each indicator are aggregated over all dike rings and accumulated across this planning horizon in order to assess the performance of the policies. 
The same set of physical flood risk policies that was applied in the original Waas case paper is employed here (Table 1). The policies focus either on flood risk reduction or on flood damage reduction. The former aims at reducing the possibility of the occurrence of flood events while the latter aims at reducing the damage incurred from inundation.

Both climate and socioeconomic uncertainties are considered. Three categories of climate scenarios, formulated by the Royal Dutch Meteorological Institute (KNMI), are incorporated: no climate change, G scenario (moderate climate change, temperature rise of $1^{\circ} \mathrm{C}$ in 2100), and Wp scenario (severe climate change, temperature rise of $2^{\circ} \mathrm{C}$ in 2100). These climate scenarios are grounded on the combination of downscaled General Climate Model and Regional Climate Model simulations used in IPCC reports, meteorological observations, and expert judgement (Van den Hurk et al., 2007). For each category, ten climate realisations are constructed by using the KNMI Rainfall Generator (Buishand \& Brandsma, 1996) in combination with the delta change approach (Lenderink et al., 2007), resulting in a total of 30 climate realisations. Each climate realisation is a 100-year time series of precipitation. In general, a more severe climate change scenario leads to higher precipitation rates, and thus higher maximum river discharges.

Table 1: Overview of original physical flood risk policies applied.

\begin{tabular}{|c|c|c|c|}
\hline No & Name & Description & Category \\
\hline 1 & No policy & Do nothing & - \\
\hline 2 & DH500 & Dike height rise to cope with a 1:500 discharge, based on measurements & Flood risk reduction \\
\hline 3 & DH1000 & $\begin{array}{l}\text { Dike height rise to cope with a 1:1000 discharge, based on } \\
\text { measurements }\end{array}$ & Flood risk reduction \\
\hline 4 & $\mathrm{DH} 1.5$ & $\begin{array}{l}\text { Dike rise: adapting to } 1.5 \text { times the second highest discharge ever } \\
\text { measured }\end{array}$ & Flood risk reduction \\
\hline 5 & RfR small & $\begin{array}{l}\text { Room for the river - Small scale: with extra side channels, the river is } \\
\text { given more space after a threshold discharge is exceeded }\end{array}$ & Flood risk reduction \\
\hline 6 & RfR medium & $\begin{array}{l}\text { Room for the river - Medium scale: with extra side channels, the river is } \\
\text { given more space after a threshold discharge is exceeded }\end{array}$ & Flood risk reduction \\
\hline 7 & RfR large & $\begin{array}{l}\text { Room for the river - Large scale: with extra side channels, the river is } \\
\text { given more space after a threshold discharge is exceeded }\end{array}$ & Flood risk reduction \\
\hline 8 & CopU & Upstream cooperation: discharges are reduced to $14.000 \mathrm{~m} 3 / \mathrm{s}$ & Flood risk reduction \\
\hline 9 & FloatH & $\begin{array}{l}\text { Floating houses: resulting in damage functions with } 10 \text { times less } \\
\text { damage for the residential land-use class }\end{array}$ & $\begin{array}{l}\text { Flood damage } \\
\text { reduction }\end{array}$ \\
\hline 10 & $\mathrm{FaC}$ & Fort cities: extra embankments around the residential area & $\begin{array}{l}\text { Flood damage } \\
\text { reduction }\end{array}$ \\
\hline 11 & Mound & $\begin{array}{l}\text { All residential area are raised by } 4 \mathrm{~m} \text {, resulting in houses on an area of } \\
\text { elevated ground }\end{array}$ & $\begin{array}{l}\text { Flood damage } \\
\text { reduction }\end{array}$ \\
\hline
\end{tabular}

The socioeconomic uncertainties take form of future land-use maps based on the work of Kwakkel et al. (2015). In this study, we use three socioeconomic scenarios: (i) no land-use claim change, (ii) deurbanisation, and (iii) urbanisation. In the deurbanisation scenario, future land-use maps are generated where the total number of residential area is reduced by $15 \%$ within the entire planning horizon. In the urbanisation scenario, the number of residential area is increased by more than $30 \%$ by the end of the simulation run. The increase and the decrease of the residential area are uniformly distributed throughout the simulation run.

\subsection{Extension for the land-use change dynamics}

We use the LandUse Scanner software (Hilferink \& Rietveld, 1999) for the utility-based land-use change model. Coupling the land-use change model entails five additional steps: 1) adjusting land-use map resolution between the land-use change model and the Environmental Impact Assessment Model, 2) differentiating between endogenous and the exogenous land-use classes, 3) defining the local suitability function for each land-use class, 4) formulating regional demand, and 5) exchanging the states between the two models in a timely manner.

The parcels in the Environmental Impact Assessment Model have a different resolution compared to the parcels in the land-use change model. In the impact assessment model, a parcel is represented by a single land-use class, 
while in the land-use change model, a parcel consists of multiple layers of land-use classes. The land-use class with the largest area in a certain parcel becomes the dominant land-use class of that parcel. Taking the example in Figure 3, as land-use class B has the largest area, it represents that parcel in the impact assessment model.

The land-use change model makes a distinction between endogenous and exogenous land-use classes (Koomen et al., 2011). Exogenous land-use classes do not undergo the local suitability calculation, and their spatial distribution is exogenously defined. Permanent land-use functions such as dikes, infrastructure, and water body/river belong to this category. Endogenous land-use classes undergo the local suitability calculation, and thus the allocation procedure, as their presence is not permanent and the spatial distribution of their utility changes over time. Residential, industry, agriculture, recreation, and greenhouse land-use classes belong to this category.

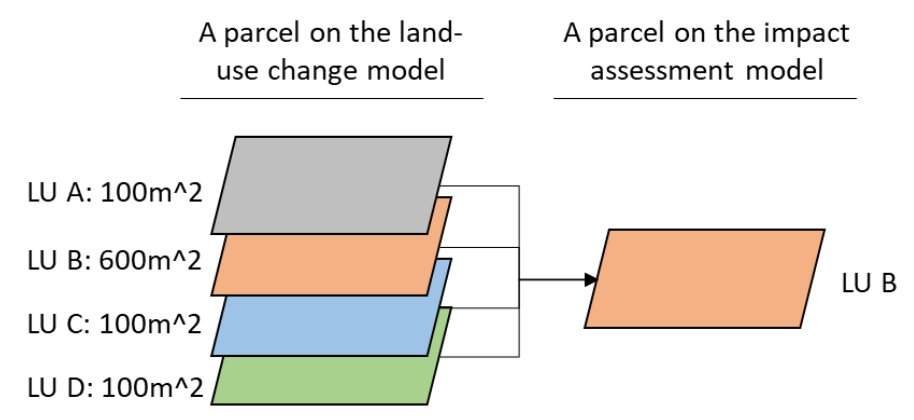

Figure 3: Schematisation of a parcel's resolution transformation.

A similar formulation of utility-based local suitability is applied to all endogenous land-use classes. The utility of a land-use class is a function of: (i) the presence of that land-use class in the parcel, (ii) the distance decay factor to the nearest same land-use class (as suggested by Diogo et al. (2015)), and (iii) the severity of the flood events from the impact assessment model. The severity is defined as a function of the flood water depth and the 'flood sensitivity threshold' of the society. If the water depth on a given parcel exceeds this threshold, the land-use actors on that parcel will re-evaluate the local suitability of that parcel. Otherwise, they will maintain their current land-use decision. The base model formulation in this study assumes a flood sensitivity threshold of zero. This makes flooding events with any severity trigger the land-use actors to adjust their decisions. The logic of the utility calculation can be found in the Supplementary Material.

The exogenous land-use maps developed in Kwakkel et al. (2015) are used as a basis for determining the regional demand in the land-use change model. Within each dike ring, the number of parcels of each land-use class in the new exogenous land-use map is subtracted from the number of parcels in the current land-use map. The difference between the two becomes the future area claim for the land-use class, to be inputted in the regional demand module of the land-use change model.

The exchange of state information between the models takes place every ten years ( $n=10$ in Figure 1b), which is similar to the time window of five to nine years as proposed by Wagner et al. (2017). The information of the occurrence of flood events in the impact assessment model within this time period is stored and is averaged by the end of the tenth year. The spatially explicit average flood water depth becomes one of the drivers that determines the local suitability (see the dashed blue line to the green box in Figure 1a). The land-use change model then creates a new land-use map. This new land-use map goes back into the impact assessment model and affects the impacts of the subsequent flood events.

\subsection{Experiment design}

Table 2 shows the five experiments carried out in order to answer different questions. The first four experiments are intended to compare the results of endogenising land-use dynamics with the exogenised land-use dynamics. The last one explores the potential of adding new land-use based policy performance indicators and a zoning policy in model-based support for climate adaptation. 
In the first two experiments, the influence of the land-use claim (socioeconomic) scenarios and the climate change scenarios is independently assessed. A full factorial design is used to sample the parameters in these experiments. There is a total of 330 unique simulation runs in each experiment ( 3 climate change scenario categories $\times 10$ precipitation realisations in each category $\times 11$ original policies (see Table 1 ) in the first experiment, 1 climate change scenario category $\times 10$ precipitation realisations $\times 3$ land-use claim scenarios $\times 11$ original policies in the second experiment).

The third experiment aims at investigating how the sensitivity of the society's land-use decisions to flood events affects the implications of endogenising land-use dynamics. To consider this factor, we introduce a new uncertain variable termed 'flood sensitivity threshold'. The value of this variable is set to zero in the other experiments, while the value will be an integer number between zero and twenty five in this experiment. The threshold value translates linearly to flood depth; a threshold value of one implies flood depth of 0.5 meter. Since flood events are climate-induced, only climate change uncertainties are considered. The full factorial design is used to sample the uncertainties.

Table 2: The five research questions and their corresponding experiment design.

\begin{tabular}{|c|c|c|c|c|c|}
\hline No & Main questions & $\begin{array}{l}\text { Uncertain } \\
\text { variables }\end{array}$ & Policies & $\begin{array}{l}\text { Endogenised } \\
\text { land-use? }\end{array}$ & $\begin{array}{l}\text { Number of } \\
\text { simulation runs }\end{array}$ \\
\hline 1 & $\begin{array}{l}\text { How does future climate change } \\
\text { development influence the impact } \\
\text { of endogenising land-use } \\
\text { dynamics? }\end{array}$ & Climate change & $\begin{array}{l}11 \text { original } \\
\text { policies }\end{array}$ & $\begin{array}{l}\text { Both - yes } \\
\text { and no }\end{array}$ & 330 \\
\hline 2 & $\begin{array}{l}\text { How does future socioeconomic } \\
\text { development influence the impact } \\
\text { of endogenising land-use } \\
\text { dynamics? }\end{array}$ & $\begin{array}{l}\text { Socioeconomic } \\
\text { (land-use claim) }\end{array}$ & $\begin{array}{l}11 \text { original } \\
\text { policies }\end{array}$ & $\begin{array}{l}\text { Both - yes } \\
\text { and no }\end{array}$ & 330 \\
\hline 3 & $\begin{array}{l}\text { How does the society's sensitivity } \\
\text { to flood events influence the } \\
\text { impact of endogenising land-use } \\
\text { dynamics? }\end{array}$ & $\begin{array}{l}\text { Climate change + } \\
\text { flood sensitivity } \\
\text { threshold }\end{array}$ & No policies & $\begin{array}{l}\text { Both - yes } \\
\text { and no }\end{array}$ & 780 \\
\hline 4 & $\begin{array}{l}\text { How does endogenising land-use } \\
\text { dynamics affect the policy } \\
\text { performance of each policy? }\end{array}$ & $\begin{array}{l}\text { Climate change + } \\
\text { Socioeconomic }\end{array}$ & $\begin{array}{l}11 \text { original } \\
\text { policies }\end{array}$ & $\begin{array}{l}\text { Both - yes } \\
\text { and no }\end{array}$ & 990 \\
\hline 5 & $\begin{array}{l}\text { What are the implications of } \\
\text { adding land-use based policies and } \\
\text { indicators on top of the standard } \\
\text { ones? }\end{array}$ & $\begin{array}{l}\text { Climate change + } \\
\text { Socioeconomic }\end{array}$ & $\begin{array}{l}11 \text { original and } \\
\text { zoning policies }\end{array}$ & Yes & 1980 \\
\hline
\end{tabular}

The fourth experiment aims at evaluating how the performance of each policy is affected by the endogenised land-use dynamics. This experiment applies a full factorial design, resulting in 90 unique parameters settings ( 3 climate change scenario categories $x 10$ precipitation realisations in each category $\times 3$ land-use claim scenarios). The performance of all policies listed in Table 1 is evaluated for each of the 90 parameters settings, resulting in a total of 990 simulation runs ( 90 parameters settings $x 11$ policies).

In the fifth experiment, an additional zoning policy is tested. The zoning policy applied here is a simple regionlevel zoning policy that aims at preventing future residential area development in flood-prone dike rings. This policy entails the displacement of residential land-use claim in dike ring 4 and 5 (regions at the south of the river) to dike ring 1, 2, and 3 (regions at the north of the river) in the regional demand module. This policy is applied concurrently with the 11 original policies, resulting in a total of 22 policies combinations. Using a full factorial design approach, this experiment setting results in 1980 simulation runs. Furthermore, an additional land-use based indicator, the weighted mean suitability (Bubeck \& Koomen, 2008), is introduced. This indicator averages the local suitability of each land-use class from all parcels on the grid. 


\section{Experiment results}

\subsection{Experiment 1 - Influences of climate change uncertainties on endogenising land-use dynamics}

Figure 4 shows the results of the first experiment. The figure condenses the outcomes of all policies. A more severe climate scenario in general has a higher precipitation rate, thus higher flood events frequency. Consequently, the outcomes always become worse when the climate scenario is more severe. When land-use dynamics are endogenised, this effect exacerbates in the cumulative total damage and cumulative area of residential sector flooded indicators, as shown in Figure $4 \mathrm{a}$ and Figure 4b. Conversely, Figure 4c shows that endogenising land-use dynamics causes a slight reduction in the damage to the agriculture sector. These results indicate that in this particular case study, endogenising land-use dynamics may lead to emerging bottom-up land-use changes, which benefit the agriculture sector at the expense of the residential sector.

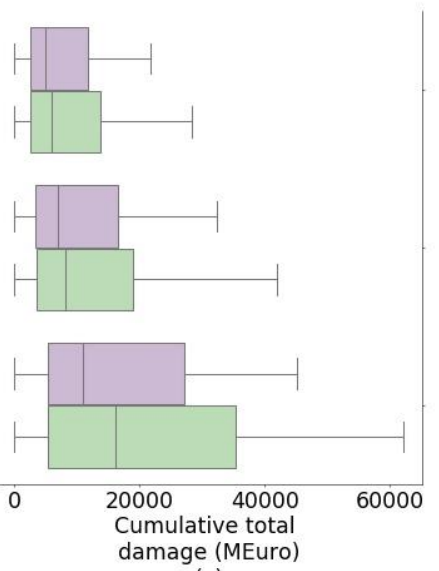

(a)

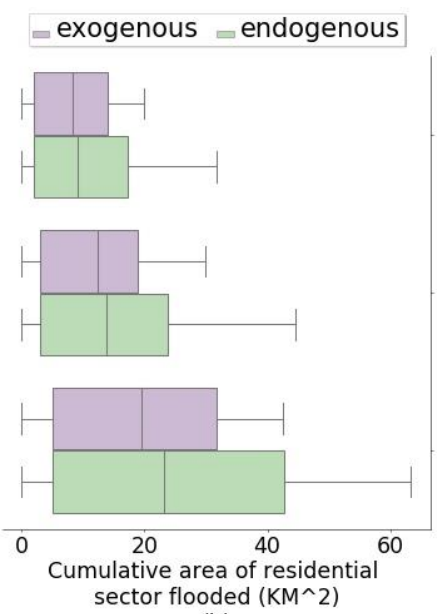

(b)

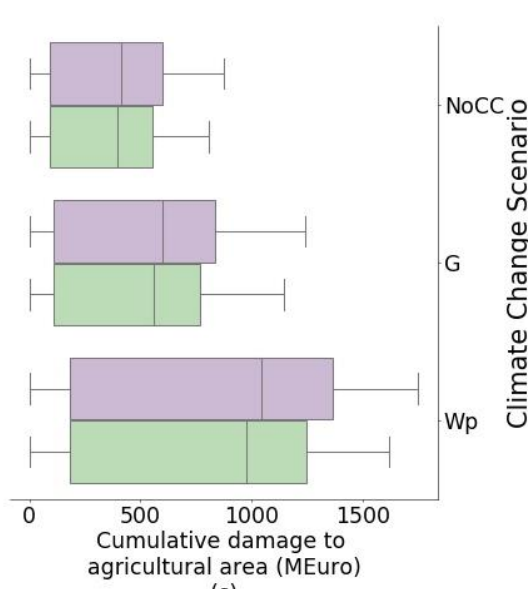

(c)

Figure 4: Implications of endogenising land-use dynamics under different climate change scenarios.

\subsection{Experiment 2 - Influences of socioeconomic uncertainties on endogenising land-use dynamics}

Figure 5 displays the results of the different socioeconomic scenarios. In the no land-use claim change and the deurbanisation scenarios, endogenising land-use dynamics increases the cumulative total damage and the area of residential sector flooded. Counterintuitively, the values of these indicators slightly decrease in the urbanisation scenario, although we would expect that there would be more residential areas in this scenario. This finding can be attributed to the difference between the exogenous runs' and the endogenous runs' spatial distribution of future residential area. In the exogenous runs, the future land-use is not allocated based on the internal dynamics of the system. Hence, the newer urban sprawl does not consider the spatial distribution of past flood events. The agriculture sector reacts oppositely. Here, by visually inspecting the graph we can see that the damage in the urbanisation scenario is reduced substantially when land-use dynamics are endogenised, while the deurbanisation scenario causes a slight increase to the damage. 


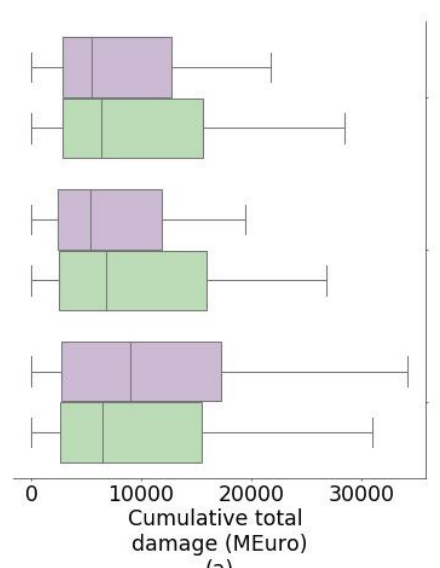

(a)

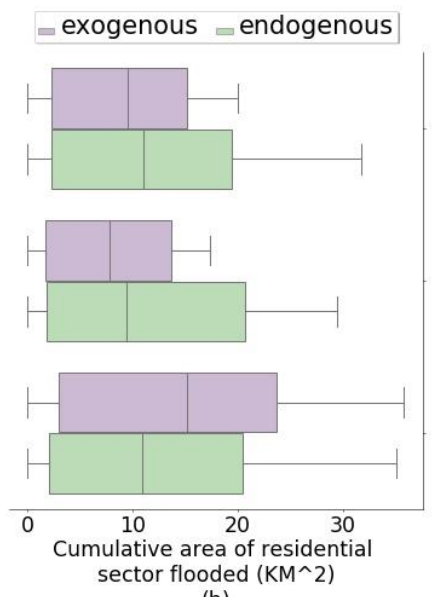

(b)

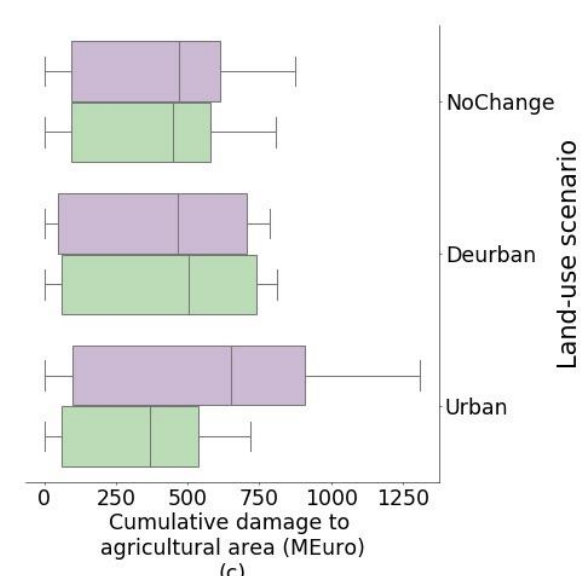

(c)

Figure 5: Implications of endogenising land-use dynamics under different socioeconomic (land-use) scenarios.

4.2 Experiment 3 - Influences of the society's sensitivity to flood events on endogenising land-use dynamics

Figure 6 shows the comparison of the cumulative total damage from the endogenous runs and the exogenous runs for different flood sensitivity thresholds. Therefore, a ratio higher than one in Figure 6 implies that the total cumulative damage from the endogenised land-use dynamics is higher compared to the exogenous land-use dynamics. The $x$-axis shows the flood sensitivity threshold. The lower the value of this threshold, the more sensitive land-use change decisions are to flood events. Figure 6 shows that the median of the damage ratio tends to be higher when the flood sensitivity threshold is low. This can be attributed to the higher occurrence of land-use changes that exacerbate the increase in total damage as described in experiment 1 and 2. After a certain point when the threshold gets higher, the damage ratio converges to one, and the range of the boxplots starts to diminish. This happens because the flood events do not trigger the society to change its land-use pattern if the severity of the events does not exceed the high flood threshold value.

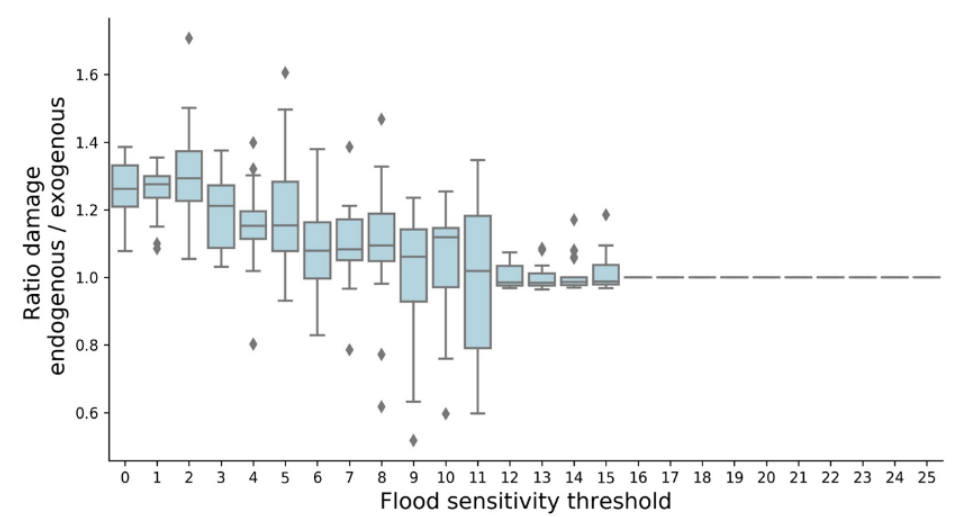

Figure 6: Ratio of cumulative damage between the endogenous runs and the exogenous runs for different flood sensitivity threshold values.

\subsection{Experiment 4-Implications of endogenising land-use dynamics to each policy}

Figure 7 compares the performance of the policies between the endogenous and the exogenous runs. There are some findings observed from this figure. First, the third indicator (the damage to agriculture sector) in most cases shows an opposite effect in comparison to the two other indicators. The only difference is for the fort cities $(\mathrm{FaC})$ policy, where the values of all the indicators decrease when land-use change is endogenised. Second, the figure gives insights into which policies are sensitive to endogenised land-use dynamics. We observe that the dikes heightening (DH500, DH1000, DH1.5) and the room for the river (RfRSmall, RfRMed, RfRLarge) policies 
are less sensitive. For flood damage reduction measures, such as floating houses (FloatH) and fort cities ( $\mathrm{FaC})$, the implication of endogenising land-use dynamics is more noticeable. Third, although the magnitude of the indicators changes, the ranking of the policies does not change if we rank them based on the median value of the indicators (the approach followed in the original work in Haasnoot et al. (2012)).
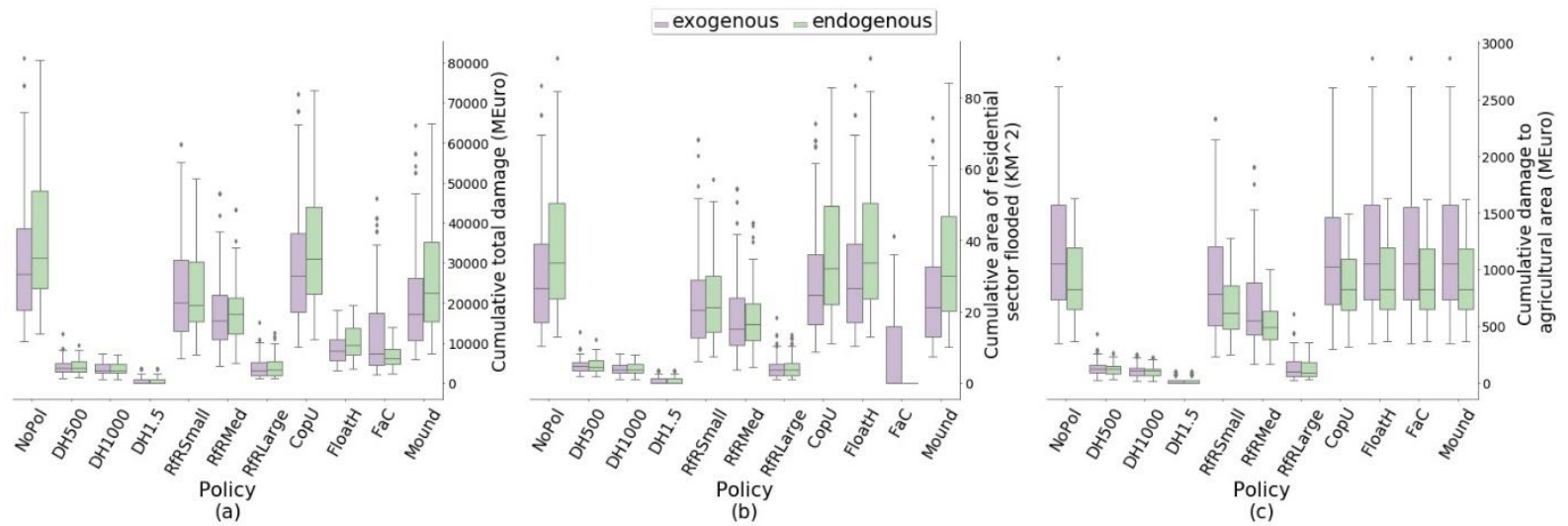

Figure 7: Implications of endogenising land-use dynamics to the performance of each policy.

\subsection{Experiment 5 - Analysis of the additional zoning policy and the land-use based indicator}

Figure 8 compares the performance of the original Policies when the additional zoning policy is applied. The zoning policy on the one hand almost does not yield any impact on the total cumulative damage from the flood risk reduction policies (Figure 8a). On the other hand, it increases the total cumulative damage of the floating house and fort cities policies. The reason behind this is that moving the protected houses to another area that is safer from floods has a drawback of leaving behind the other land-use classes vulnerable in the flood prone area. In the long run, more flood events hit the other unprotected land-use classes in the flood prone area, in turn incurring higher total damage. Figure $8 \mathrm{~b}$ shows that the zoning policy proves to be effective in reducing the cumulative area of residential sector flooded, which is a conceivable result as the houses are moved to regions that are safer from flood events. Unsurprisingly, Figure $8 \mathrm{c}$ shows that the zoning policy has almost no effect to the agriculture sector.

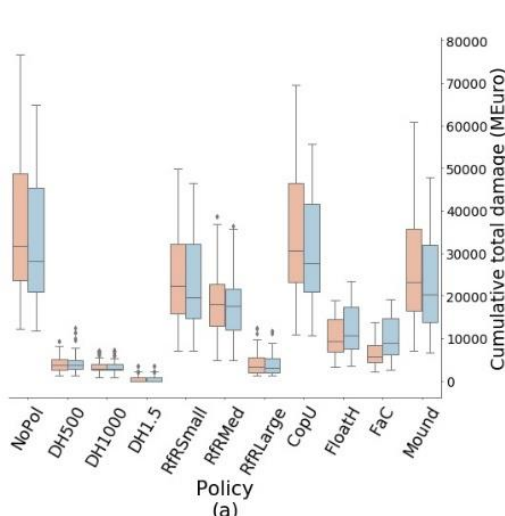

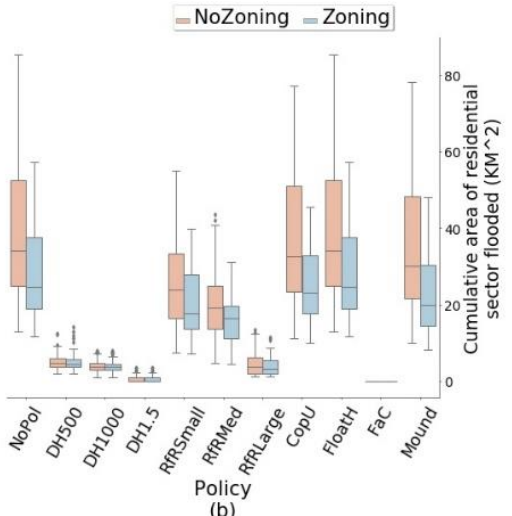

(b)

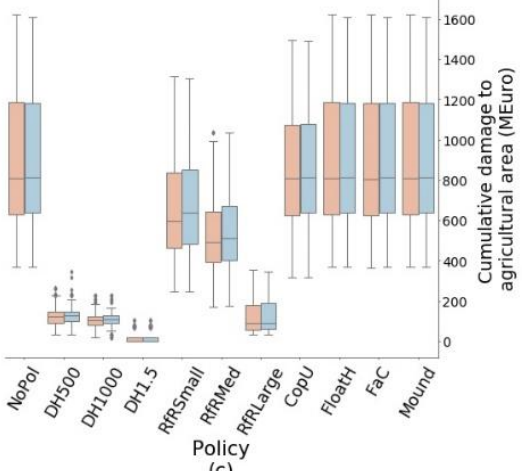

(c)

Figure 8: Implications of including a zoning policy in addition to the original policies.

Figure 9 contrasts the weighted mean suitability of each land-use class when the zoning policy is in place. The weighted mean suitability of each land-use class is an example of a disaggregated, actor-specific policy performance indicators that can be calculated in models used for adaptation planning. Each line in the figure represents the median of the weighted mean suitability values from a policy. We normalise the value in order to ease the comparison, as the concept of the local suitability itself has to be treated in a relative manner (Hilferink \& Rietveld, 1999; Koomen et al., 2015). One clear pattern that we can observe here is that the zoning policy substantially increases the suitability of the residential area. 


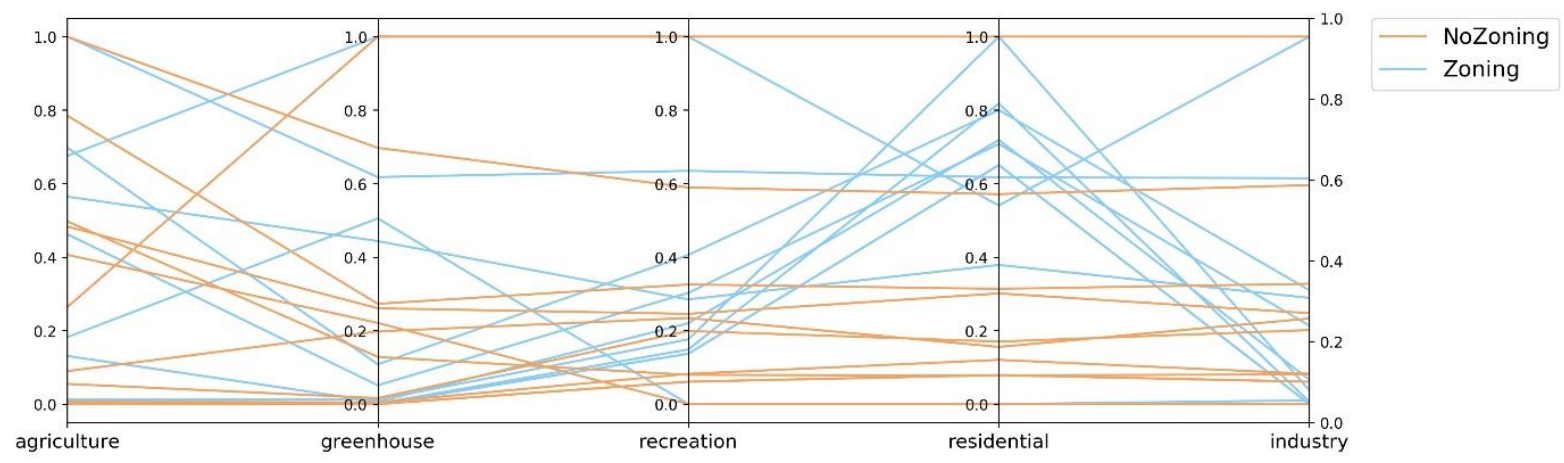

Figure 9: Parallel plot of the weighted mean suitability of the land-use classes. Each blue and orange line represents the median result of a single original policies (see Table 1).

\section{Discussion}

\subsection{What are the implications of endogenising land-use dynamics in model-based support for climate adaptation?}

We find three implications of endogenising land-use dynamics: it affects the performance of the policies, enables the evaluation of land-use based zoning policies, and broadens the types of outcomes that can be evaluated.

First, we can see the implications to the performance of the policies by observing (i) the changes in the ranking of preferred policies and (ii) the changes in the absolute values of the policy performance indicators. We observe that the ranking does not change if we rank them based on the median value of the indicators. It might change slightly if we also take into account the statistical dispersion of the indicators. For instance, from Figure $7 \mathrm{~b}$ we see that endogenising land-use dynamics diminishes the variance of the fort cities policy (FaC), making this policy the most preferable one. With respect to the changes in the absolute values of the indicators, we observe that the numbers may change when land-use dynamics are endogenised. This finding supports previous studies that show that failures to capture this bottom-up response in climate adaptation studies may lead to implausible policy conclusions (Cass, 2018; Di Baldassarre et al., 2016; Wada et al., 2017). This becomes important when the aim of the climate adaptation study is not only to rank policies, but also to assess their cost-benefit ratio. In that case, failing to better characterise the policy's performance may lead to a different conclusion on the attractiveness of the investments.

Second, by endogenising land-use change we can consider land-use zoning policies. In contrast to physical flood risk policies, zoning policies incur lower costs. This makes the combination of zoning policies and physical policies interesting. Such combinations are rarely evaluated in model-based climate adaptation studies (Newman et al., 2017), while they are relevant in practice. In this paper, we introduce an additional zoning policy where we restrict further residential land-use development in the flood prone area.

The zoning policy is effective in improving the weighted mean suitability of the residential land-use actor and reducing the cumulative area of residential sector flooded. However, the impact of the zoning policy varies across the different physical policies. When the floating houses (FloatH) and fort cities ( $\mathrm{FaC}$ ) policies are applied, the zoning policy results in a higher total cumulative damage. These actor-specific physical policies substantially improve the resistance of the residential sector to flood events, thus counteracting the also actor-specific zoning policy. The increase in total cumulative damage can also be attributed to the damages experienced by the other land-use classes, especially the industry sector that has a relatively high damage factor. These land-use classes are left vulnerable in flood prone dike rings. This raises a flood risk transfer problem, which is a prominent ethical issue in flood risk management (Doorn, 2014a, 2014b). Endogenising land-use dynamics enables the exploration of this risks transfer problem transparently. 
Third, by endogenising land use change we enable a broader perspective in the evaluation of alternative climate adaptation plans. Here, we use the weighted mean suitability to evaluate the utility of each land-use class. Incorporating this indicator provides two benefits. First, this indicator can approximate the distributional impacts of policies (i.e., disaggregated, actor-based policy performance indicators). This intra-generational distributional problem has been one of the key ethical challenges in climate adaptation planning (Donna, 2016; Kolstad et al., 2014). Based on this indicator, an aggregated system-level inclusivity indicator can be further developed in many ways, for instance by calculating the discrepancy between the better-off and the worse-off land-use actors. Second, we can explicitly explore the multi-actor trade-offs of policies. Analytical techniques derived from ongoing works on multi-stakeholder model-based robustness analysis can be adapted for this purpose (e.g. Herman et al., 2014; Trindade et al., 2017; Zeff et al., 2016).

The area of residential sector flooded and the cumulative damage to the agriculture sector can be categorised as actor-based indicators. However, acknowledging so could be misleading as we only see the utility from the environmental perspective. The concept underlying the utility-based land-use change model can help in better apprehending the utility of the land-use actors from environment, social, and economics perspectives. The same reasoning also applies to zoning policies. Practically speaking, we can set rules in the exogenous land-use scenarios in such a way that future new residential areas do not sprawl in the flood-prone area. However, we would have missed the emerging bottom-up responses of the land-use actors. This in turn might result in a misleading policy conclusion especially if the study is done for regions where land-use functions are highly dynamic.

\subsection{When does endogenising land-use dynamics become (ir)relevant?}

We evaluate four factors that have the potential to influence the relevance of endogenising land-use dynamics: severity of future climate change, future socioeconomic development characterised as (de)urbanisation scenarios, society's responsiveness to climate events, and the nature of the policies that decision makers want to appraise. We evaluate them with regard to the changes in magnitude of the policy performance indicators, when compared to simulation runs that exogenise the land-use dynamics. If the results do not differ much, endogenising land-use dynamics can be considered as irrelevant.

In more severe climate change scenarios, the $G$ and the $W p$ scenarios, the impact of endogenising land-use dynamics is larger. In these scenarios, the frequency of flood events is generally higher. The more frequent flood events trigger the society to adjust their land-use pattern. In the land-use change model, it is assumed that different land-use classes responded to the flood events differently. A slightly higher flood sensitivity parameter value is given to land-use classes whose flood damage function was higher in the original Waas case (e.g., higher values for the residential and the industry sectors as their original flood damage function is larger). Consequently, when flood events occur, the residential and the industry land-use classes are more affected, in comparison to the agriculture and greenhouses land-use classes. This triggers an agglomeration for the residential and industry land-use classes. The agglomeration increases the number of dominant residential and industry land-use parcels while decreases the number of dominant agriculture parcels. In combination with the higher flood damage function to these land-use classes, the agglomeration results in higher total cumulative damage.

When urbanisation is expected in a particular area, surprisingly, endogenising land-use dynamics leads to a lower total cumulative damage in comparison to the exogenised case. This is explained by the spatial distribution of the new residential area in the exogenous land-use maps. The new residential area from the exogenous maps sprawls uniformly around the smaller cities in the delta, where the elevation is relatively low. Conversely, when the land-use dynamics are endogenised, the new residential area tends to sprawl near the large city in the southeast part of the delta (see Figure 2). This area in general has higher elevation, thus safer from flood. Therefore, the effect observed here cannot be generalised, as it is strongly influenced by the spatial pattern of the exogenous land-use maps. Nevertheless, the insight shows that by endogenising land-use dynamics we can observe the area where new residential land-use might potentially emerge. This information can be used to develop further zoning policies for reducing climate impacts. Such an approach is typical in the Dutch flood planning context (De Moel et al., 2011).

The responsiveness of a society to climate events, characterised by the flood sensitivity threshold parameter, strongly affects the implication of endogenising land-use dynamics. A higher threshold results in indifferent 
outcomes for both the exogenised and the endogenised case. This suggests that endogenising land-use dynamics becomes more relevant in a society that is highly responsive to climate events (i.e. has low flood sensitivity threshold). As an example, endogenising land-use dynamics is relevant for climate adaptation planning in the Vietnam Mekong Delta, where extreme weather events have empirically been proven to be one of the key determinants in people's land-use decisions (Chapman \& Tri, 2018; Kim \& Le Minh, 2017). Failure in capturing such phenomenon in the integrated assessment model resembles the 'policy myopia' problem (Nair \& Howlett, 2017), which in turn might result in misleading policy conclusions. Conversely, it is less relevant for climate adaptation planning in Alba town, Italy, where recurring flood events have not had significant influence to the land-use dynamics of the city (Luino et al., 2012).

The nature of the policies to be evaluated also plays a role in the relevance of endogenising land-use dynamics. If the benefit of a policy does not disproportionately affect certain land-use actors, endogenising land-use dynamics tends to give only marginal effect. We observe this in the performance of the dikes heightening measures and the room for the river, which benefits are experienced by all land-use actors. Consequently, as shown in Figure 7, the total cumulative damages resulting from the endogenised and the exogenised land-use dynamics do not differ much. If a policy targets specific land-use actors, such as in the case in fort cities and floating houses, the dynamics of the land-use actors affects the performance of the policy. Hence, the effect of endogenising land-use dynamics becomes more profound.

\section{Conclusions}

Although models used for supporting climate change are becoming even more integrated (Harrison et al., 2016), future land-use maps are still often treated as an exogenous factor. Strong interconnectedness between landuse change and climate change has long been acknowledged (Dale, 1997). Ignoring the interaction between the environment and the society (in this case embodied by the land-use) can result in miscalculation of the impacts of adaptation and might limit the adaptation options that are considered. Motivated by these facts, this paper explores the merits of using utility-based land-use change model for endogenising land-use dynamics in a spatially explicit integrated assessment model.

Three implications of endogenising land-use dynamics have been identified: (i) changes in the performance of policies, (ii) the possibility of including land-use based zoning policies, and (iii) the inclusion of disaggregated, actor-level policy performance indicators. With respect to the first point, the ranking of policies did not substantially change while the absolute scores of the policy performance indicators did change in some cases. With respect to the second point, this approach enabled the evaluation of zoning policies. The performance of such policies has only been descriptively evaluated in separate independent studies, often neglecting the infrastructural policies. By using the approach presented here, the performance could be evaluated in a quantitative and integrative manner. Moreover, the land-use maps generated by the model can be used as a starting point to identify potential land-use based policies. With respect to the third point, the weighted mean suitability was used to evaluate the actors' utility not only from the environmental perspective but also from the social and economic perspectives. These indicators can be a starting point to evaluate the distributional impacts of alternative policies.

We found three factors that might affect the implications of endogenising land-use dynamics in model-based decision support for climate adaptation described above. We evaluated the effect by observing how the policies performance indicators changed. The analysis suggests that the implications of endogenising land use are more profound if (i) more severe climate change is expected, (ii) society is reactive or sensitive to climate events, and (iii) some of the policies are targeting specific actor groups within the society. Special attention should be put to point (ii). In a society that is sensitive to climate events, changing land-use functions is one form of autonomous adaptation (see e.g. Ahmed, 2011; Smajgl et al., 2015; Thai et al., 2014). Failing to capture these dynamics may overlook the adaptive responses of the people, and thus may have a profound influence on the conclusions of the study.

Although endogenised land-use dynamics here are specifically investigated in the context of flood risk adaptation planning, the approach can be used for other climate adaptation contexts. The importance of dynamically adding land-use change in integrated assessment models has been put forward in studies on watershed planning (Wagner et al., 2017; Zhang et al., 2018), desertification (Xu et al., 2016), ecological 
vulnerability (Zhang et al., 2017), agricultural systems (Li et al., 2018), and livestock production systems (Havlík et al., 2014). In order to endogenise land-use dynamics in other contexts, the key challenge is to identify the relevant states to be exchanged and the right time integration window between land-use and the environment systems. This study has shown merits of making land-use dynamics endogenous in a theoretical case study as a proof of concept. The challenge now is to apply this approach to a real world case study.

\section{References}

Abd El-Kawy, O. R., Rød, J. K., Ismail, H. A., \& Suliman, A. S. (2011). Land use and land cover change detection in the western Nile delta of Egypt using remote sensing data. Applied Geography, 31(2), 483-494. doi:10.1016/j.apgeog.2010.10.012

Ahmed, A. (2011). Some of the major environmental problems relating to land use changes in the coastal areas of Bangladesh: A review. Journal of Geography and Regional Planning, 4(1), 1-8.

Antle, J. M., Capalbo, S. M., Elliott, E. T., Hunt, H. W., Mooney, S., \& Paustian, K. H. (2001). Research Needs for Understanding and Predicting the Behavior of Managed Ecosystems: Lessons from the Study of Agroecosystems. Ecosystems, 4(8), 723-735. doi:10.1007/s10021-001-0041-0

Audsley, E., Trnka, M., Sabaté, S., Maspons, J., Sanchez, A., Sandars, D., Balek, J., \& Pearn, K. (2015). Interactively modelling land profitability to estimate European agricultural and forest land use under future scenarios of climate, socioeconomics and adaptation. Climatic Change, 128(3), 215-227. doi:10.1007/s10584-014-1164-6

Barton, R. R. (1998). Simulation metamodels. Paper presented at the Proceedings of the 30th conference on Winter simulation, Washington DC, USA.

Brown, D. G., Walker, R., Manson, S., \& Seto, K. (2004). Modeling Land Use and Land Cover Change. In G. Gutman, A. C. Janetos, C. O. Justice, E. F. Moran, J. F. Mustard, R. R. Rindfuss, D. Skole, B. L. Turner, \& M. A. Cochrane (Eds.), Land Change Science: Observing, Monitoring and Understanding Trajectories of Change on the Earth's Surface (pp. 395409). Dordrecht: Springer Netherlands.

Bubeck, P., \& Koomen, E. (2008). The use of quantitative evaluation measures in land-use change projections: An inventory of indicators available in the Land Use Scanner. Retrieved from Amsterdam, The Netherlands: https://spinlab.vu.nl/wp-content/uploads/2016/09/Bubeck_Koomen_SL07_v2.pdf

Buishand, T., \& Brandsma, T. (1996). Rainfall generator for the rhine catchment: a feasibility study. Retrieved from De Bilt: http://bibliotheek.knmi.nl/knmipubTR/TR183.pdf

Buurman, J., \& Babovic, V. (2016). Adaptation Pathways and Real Options Analysis: An approach to deep uncertainty in climate change adaptation policies. Policy and Society, 35(2), 137-150. doi:10.1016/j.polsoc.2016.05.002

Carmona, G., Varela-Ortega, C., \& Bromley, J. (2013). Supporting decision making under uncertainty: Development of a participatory integrated model for water management in the middle Guadiana river basin. Environmental Modelling \& Software, 50, 144-157. doi:10.1016/j.envsoft.2013.09.007

Cass, O. (2018). Overheated: How Flawed Analyses Overestimate the Costs of Climate Change. Retrieved from New York, United States of America: https://www.manhattan-institute.org/sites/default/files/R-OC-0318.pdf

Chambwera, M., Heal, G., Dubeux, C., Hallegatte, S., Leclerc, L., Markandya, A., McCarl, B. A., Mechler, R., \& Neumann, J. E. (2014). Chapter 17 - Economics of adaptation. In Climate Change 2014: Impacts, Adaptation, and Vulnerability. Part A: Global and Sectoral Aspects. Contribution of Working Group II to the Fifth Assessment Report of the IPCC: Cambridge University Press.

Chang, Y. C., Hong, F. W., \& Lee, M. T. (2008). A system dynamic based DSS for sustainable coral reef management in Kenting coastal zone, Taiwan. Ecological Modelling, 211(1), 153-168. doi:10.1016/j.ecolmodel.2007.09.001

Chapman, A., \& Tri, V. P. D. (2018). Climate change is triggering a migrant crisis in Vietnam. Retrieved from https://theconversation.com/climate-change-is-triggering-a-migrant-crisis-in-vietnam88791?utm_source=twitter\&utm_medium=twitterbutton

Cofala, J., Amann, M., Asman, W. A. H., Bertok, I., Heyes, C., Hoeglund-Isaksson, L., Klimont, Z., Schoepp, W., \& Wagner, F. (2010). Integrated assessment of air pollution and greenhouse gases mitigation in Europe. Archives of Environmental Protection, 36(1), 29-39.

Dale, V. H. (1997). The relationship between land-use change and climate change. Ecological Applications, 7(3), 753-769. doi:10.1890/1051-0761(1997)007[0753:TRBLUC]2.0.CO;2

Davis, P. K., \& Bigelow, J. H. (2003). Motivated metamodels: Synthesis of cause-effect reasoning and statistical metamodeling. Retrieved from Santa Monica, United States of America: http://www.dtic.mil/get-trdoc/pdf?AD=ADA411888

De Moel, H., Aerts, J. C. J. H., \& Koomen, E. (2011). Development of flood exposure in the Netherlands during the 20th and 21st century. Global Environmental Change, 21(2), 620-627. doi:10.1016/j.gloenvcha.2010.12.005

Dessai, S., Hulme, M., Lempert, R., \& Pielke Jr, R. (2009). Climate prediction: a limit to adaptation. Adapting to climate change: thresholds, values, governance, 64-78.

Dessai, S., \& van der Sluijs, J. P. (2007). Uncertainty and climate change adaptation: A scoping study (Vol. 2007): Copernicus Institute for Sustainable Development and Innovation, Department of Science Technology and Society. 
Di Baldassarre, G., Brandimarte, L., \& Beven, K. (2016). The seventh facet of uncertainty: wrong assumptions, unknowns and surprises in the dynamics of human-water systems. Hydrological Sciences Journal, 61(9), 1748-1758. doi:10.1080/02626667.2015.1091460

Diogo, V., Koomen, E., \& Kuhlman, T. (2015). An economic theory-based explanatory model of agricultural land-use patterns: The Netherlands as a case study. Agricultural Systems, 139, 1-16. doi:10.1016/j.agsy.2015.06.002

Donna, G. (2016). The spatial distribution of extreme climate events, another climate inequity for the world's most vulnerable people. Environmental Research Letters, 11(9), 091002.

Doorn, N. (2014a). The Blind Spot in Risk Ethics: Managing Natural Hazards. Risk Analysis, 35(3), 354-360. doi:10.1111/risa.12293

Doorn, N. (2014b). Equity and the Ethics of Water Governance. In A. V. Gheorghe, M. Masera, \& P. F. Katina (Eds.), Infranomics: Sustainability, Engineering Design and Governance (pp. 155-164). Switzerland: Springer International Publishing.

Fant, C., Schlosser, C. A., Gao, X., Strzepek, K., \& Reilly, J. (2016). Projections of Water Stress Based on an Ensemble of Socioeconomic Growth and Climate Change Scenarios: A Case Study in Asia. PLoS ONE, 11(3), e0150633. doi:10.1371/journal.pone.0150633

Filatova, T., Verburg, P. H., Parker, D. C., \& Stannard, C. A. (2013). Spatial agent-based models for socio-ecological systems: Challenges and prospects. Environmental Modelling \& Software, 45, 1-7. doi:10.1016/j.envsoft.2013.03.017

Füssel, H. M. (2007). Adaptation planning for climate change: concepts, assessment approaches, and key lessons. Sustainability Science, 2(2), 265-275. doi:10.1007/s11625-007-0032-y

Gao, L., \& Bryan, B. A. (2017). Finding pathways to national-scale land-sector sustainability. Nature, 544(7649), $217-222$. doi:10.1038/nature21694

Haasnoot, M., Middelkoop, H., Offermans, A., Van Beek, E., \& Van Deursen, W. P. A. (2012). Exploring pathways for sustainable water management in river deltas in a changing environment. Climatic Change, 115(3-4), 795-819.

Haasnoot, M., Middelkoop, H., van Beek, E., \& van Deursen, W. P. A. (2009). A method to develop sustainable water management strategies for an uncertain future. Sustainable Development, 19(6), 369-381. doi:10.1002/sd.438

Haasnoot, M., Van Deursen, W. P. A., Guillaume, J. H. A., Kwakkel, J. H., van Beek, E., \& Middelkoop, H. (2014). Fit for purpose? Building and evaluating a fast, integrated model for exploring water policy pathways. Environmental Modelling \& Software, 60, 99-120. doi:10.1016/j.envsoft.2014.05.020

Hall, J. W., Dawson, R. J., Barr, S. L., Batty, M., Bristow, A. L., Carney, S., Dagoumas, A., Ford, A., Harpham, C., \& Tight, M. R. (2010). City-scale integrated assessment of climate impacts, adaptation and mitigation. Energy efficient cities: Assessment tools and benchmarking practices, 43-64.

Hamilton, S. H., ElSawah, S., Guillaume, J. H. A., Jakeman, A. J., \& Pierce, S. A. (2015). Integrated assessment and modelling: Overview and synthesis of salient dimensions. Environmental Modelling \& Software, 64, 215-229. doi:10.1016/j.envsoft.2014.12.005

Harrison, P. A., Dunford, R. W., Holman, I. P., \& Rounsevell, M. D. A. (2016). Climate change impact modelling needs to include cross-sectoral interactions. Nature Climate Change, 6, 885. doi:10.1038/nclimate3039

Hauer, M. E. (2017). Migration induced by sea-level rise could reshape the US population landscape. Nature Climate Change, 7, 321. doi:10.1038/nclimate3271

Havlík, P., Valin, H., Herrero, M., Obersteiner, M., Schmid, E., Rufino, M. C., Mosnier, A., Thornton, P. K., Böttcher, H., Conant, R. T., Frank, S., Fritz, S., Fuss, S., Kraxner, F., \& Notenbaert, A. (2014). Climate change mitigation through livestock system transitions. Proceedings of the National Academy of Sciences, 111(10), 3709.

Herman, J. D., Zeff, H. B., Reed, P. M., \& Characklis, G. W. (2014). Beyond optimality: Multistakeholder robustness tradeoffs for regional water portfolio planning under deep uncertainty. Water Resources Research, 50(10), 7692-7713. doi:10.1002/2014WR015338

Hilferink, M., \& Rietveld, P. (1999). LAND USE SCANNER: An integrated GIS based model for long term projections of land use in urban and rural areas. Journal of Geographical Systems, 1(2), 155-177. doi:10.1007/s101090050010

Holman, I. P., Harrison, P. A., \& Metzger, M. J. (2016). Cross-sectoral impacts of climate and socio-economic change in Scotland: implications for adaptation policy. Regional Environmental Change, 16(1), 97-109. doi:10.1007/s10113014-0679-8

Karssenberg, D., Schmitz, O., Salamon, P., de Jong, K., \& Bierkens, M. F. P. (2010). A software framework for construction of process-based stochastic spatio-temporal models and data assimilation. Environmental Modelling \& Software, 25(4), 489-502. doi:10.1016/j.envsoft.2009.10.004

Kim, O. L. T., \& Le Minh, T. (2017). Correlation between climate change impacts and migration decisions in Vietnamese Mekong Delta. International Journal of Innovative Science, Engineering \& Technology.

Kok, M. (2005). Standaardmethode 2005. Schade en slachtoffers als gevolg van overstromingen. (Standard method 2005. Damage and casualties caused by flooding). Lelystad: HKV.

Kolstad, C., Urama, K., Broome, J., Bruvoll, A., Cariño-Olvera, M., Fullerton, D., Gollier, C., Hanemann, W. M., Hassan, R., \& Jotzo, F. (2014). Social, economic and ethical concepts and methods. Climate Change 2014: Mitigation of Climate Change, 173-248.

Koomen, E., Diogo, V., Dekkers, J., \& Rietveld, P. (2015). A utility-based suitability framework for integrated local-scale landuse modelling. Computers, Environment and Urban Systems, 50, 1-14. doi:10.1016/j.compenvurbsys.2014.10.002

Koomen, E., Hilferink, M., \& Borsboom-van Beurden, J. (2011). Introducing land use scanner. In Land-use modelling in planning practice (pp. 3-21): Springer, Dordrecht. 
Kwakkel, J. H., Haasnoot, M., \& Walker, W. E. (2015). Developing dynamic adaptive policy pathways: a computer-assisted approach for developing adaptive strategies for a deeply uncertain world. Climatic Change, 132(3), 373-386. doi:10.1007/s10584-014-1210-4

Kwakkel, J. H., Haasnoot, M., \& Walker, W. E. (2016). Comparing Robust Decision-Making and Dynamic Adaptive Policy Pathways for model-based decision support under deep uncertainty. Environmental Modelling \& Software, 86, 168183. doi:10.1016/j.envsoft.2016.09.017

Laliberté, E., Wells, J. A., DeClerck, F., Metcalfe, D. J., Catterall, C. P., Queiroz, C., Aubin, I., Bonser, S. P., Ding, Y., Fraterrigo, J. M., McNamara, S., Morgan, J. W., Merlos, D. S., Vesk, P. A., \& Mayfield, M. M. (2010). Land-use intensification reduces functional redundancy and response diversity in plant communities. Ecology Letters, 13(1), 76-86. doi:10.1111/j.1461-0248.2009.01403.x

Lambin, E. F., \& Meyfroidt, P. (2010). Land use transitions: Socio-ecological feedback versus socio-economic change. Land Use Policy, 27(2), 108-118. doi:10.1016/j.landusepol.2009.09.003

Lempert, R. J. (2003). Shaping the next one hundred years: new methods for quantitative, long-term policy analysis: Rand Corporation.

Lenderink, G., Buishand, A., \& van Deursen, W. (2007). Estimates of future discharges of the river Rhine using two scenario methodologies: direct versus delta approach. Hydrol. Earth Syst. Sci., 11(3), 1145-1159. doi:10.5194/hess-11-11452007

Lesschen, J. P., Verburg, P. H., \& Staal, S. J. (2005). Statistical methods for analysing the spatial dimension of changes in land use and farming systems: International Livestock Research Institute.

Li, S., Juhász-Horváth, L., Pintér, L., Rounsevell, M. D. A., \& Harrison, P. A. (2018). Modelling regional cropping patterns under scenarios of climate and socio-economic change in Hungary. Science of the Total Environment, 622-623, 1611-1620. doi:10.1016/j.scitotenv.2017.10.038

Luino, F., Turconi, L., Petrea, C., \& Nigrelli, G. (2012). Uncorrected land-use planning highlighted by flooding: the Alba case study (Piedmont, Italy). Natural Hazards and Earth System Sciences, 12(7), 2329.

Maier, H. R., Guillaume, J. H. A., van Delden, H., Riddell, G. A., Haasnoot, M., \& Kwakkel, J. H. (2016). An uncertain future, deep uncertainty, scenarios, robustness and adaptation: How do they fit together? Environmental Modelling \& Software, 81, 154-164. doi:10.1016/j.envsoft.2016.03.014

Manocha, N., \& Babovic, V. (2018). Sequencing Infrastructure Investments under Deep Uncertainty Using Real Options Analysis. Water, 10(2). doi:10.3390/w10020229

McPhail, C., Maier, H. R., Kwakkel, J. H., Giuliani, M., Castelletti, A., \& Westra, S. (2018). Robustness Metrics: How Are They Calculated, When Should They Be Used and Why Do They Give Different Results? Earth's Future, 6(2), 169-191. doi:10.1002/2017EF000649

Moss, R. H., Edmonds, J. A., Hibbard, K. A., Manning, M. R., Rose, S. K., van Vuuren, D. P., Carter, T. R., Emori, S., Kainuma, M., Kram, T., Meehl, G. A., Mitchell, J. F. B., Nakicenovic, N., Riahi, K., Smith, S. J., Stouffer, R. J., Thomson, A. M., Weyant, J. P., \& Wilbanks, T. J. (2010). The next generation of scenarios for climate change research and assessment. nature, 463, 747. doi:10.1038/nature08823

Nair, S., \& Howlett, M. (2017). Policy myopia as a source of policy failure: Adaptation and policy learning under deep uncertainty. Policy \& Politics, 45(1), 103-118. doi:10.1332/030557316X14788776017743

Newman, J. P., Maier, H. R., Riddell, G. A., Zecchin, A. C., Daniell, J. E., Schaefer, A. M., van Delden, H., Khazai, B., O'Flaherty, M. J., \& Newland, C. P. (2017). Review of literature on decision support systems for natural hazard risk reduction: Current status and future research directions. Environmental Modelling \& Software, 96, 378-409. doi:10.1016/j.envsoft.2017.06.042

Niemeijer, D., \& de Groot, R. S. (2008). A conceptual framework for selecting environmental indicator sets. Ecological Indicators, 8(1), 14-25. doi:10.1016/j.ecolind.2006.11.012

Overmars, K. P., de Groot, W. T., \& Huigen, M. G. A. (2007). Comparing Inductive and Deductive Modeling of Land Use Decisions: Principles, a Model and an Illustration from the Philippines. Human Ecology, 35(4), 439-452. doi:10.1007/s10745-006-9101-6

Overmars, K. P., Verburg, P. H., \& Veldkamp, T. (2007). Comparison of a deductive and an inductive approach to specify land suitability in a spatially explicit land use model. Land Use Policy, 24(3), 584-599. doi:doi.org/10.1016/j.landusepol.2005.09.008

Oxley, T., Dore, A. J., ApSimon, H., Hall, J., \& Kryza, M. (2013). Modelling future impacts of air pollution using the multi-scale UK Integrated Assessment Model (UKIAM). Environment International, 61, 17-35. doi:10.1016/j.envint.2013.09.009

Patt, A. G., van Vuuren, D. P., Berkhout, F., Aaheim, A., Hof, A. F., Isaac, M., \& Mechler, R. (2010). Adaptation in integrated assessment modeling: where do we stand? Climatic Change, 99(3), 383-402. doi:10.1007/s10584-009-9687-y

Qureshi, M. E., Whitten, S. M., Mainuddin, M., Marvanek, S., \& Elmahdi, A. (2013). A biophysical and economic model of agriculture and water in the Murray-Darling Basin, Australia. Environmental Modelling \& Software, 41, 98-106. doi:10.1016/j.envsoft.2012.11.007

Refsgaard, J. C., van der Sluijs, J. P., Højberg, A. L., \& Vanrolleghem, P. A. (2007). Uncertainty in the environmental modelling process - A framework and guidance. Environmental Modelling \& Software, 22(11), 1543-1556. doi:10.1016/j.envsoft.2007.02.004

Rotmans, J., De Boois, H., \& Swart, R. J. (1990). An integrated model for the assessment of the greenhouse effect: The Dutch approach. Climatic Change, 16(3), 331-356. doi:10.1007/BF00144508 
Schmitz, O., Karssenberg, D., de Jong, K., de Kok, J.-L., \& de Jong, S. M. (2013). Map algebra and model algebra for integrated model building. Environmental Modelling \& Software, 48, 113-128. doi:10.1016/j.envsoft.2013.06.009

Schwanitz, V. J. (2013). Evaluating integrated assessment models of global climate change. Environmental Modelling \& Software, 50, 120-131. doi:10.1016/j.envsoft.2013.09.005

Serneels, S., \& Lambin, E. F. (2001). Proximate causes of land-use change in Narok District, Kenya: a spatial statistical model. Agriculture, Ecosystems \& Environment, 85(1), 65-81. doi:10.1016/S0167-8809(01)00188-8

Smajgl, A., Toan, T. Q., Nhan, D. K., Ward, J., Trung, N. H., Tri, L. Q., Tri, V. P. D., \& Vu, P. T. (2015). Responding to rising sea levels in the Mekong Delta. Nature Climate Change, 5(2), 167-174. doi:10.1038/nclimate2469

Stonestrom, D. A., Scanlon, B. R., \& Zhang, L. (2009). Introduction to special section on Impacts of Land Use Change on Water Resources. Water Resources Research, 45(7), n/a-n/a. doi:10.1029/2009WR007937

Swetnam, R. D., Fisher, B., Mbilinyi, B. P., Munishi, P. K. T., Willcock, S., Ricketts, T., Mwakalila, S., Balmford, A., Burgess, N. D., Marshall, A. R., \& Lewis, S. L. (2011). Mapping socio-economic scenarios of land cover change: A GIS method to enable ecosystem service modelling. Journal of Environmental Management, 92(3), 563-574. doi:10.1016/j.jenvman.2010.09.007

Taylor, K. E., Stouffer, R. J., \& Meehl, G. A. (2012). An overview of CMIP5 and the experiment design. Bulletin of the American Meteorological Society, 93(4), 485-498.

Thai, D. V. H., Cong, V. T., Nestmann, F., Oberle, P., \& Trung, N. N. (2014). Land use based flood hazards analysis for the Mekong Delta. Paper presented at the The 19th IAHR-APD Congress, Hanoi, Vietnam.

Trindade, B. C., Reed, P. M., Herman, J. D., Zeff, H. B., \& Characklis, G. W. (2017). Reducing regional drought vulnerabilities and multi-city robustness conflicts using many-objective optimization under deep uncertainty. Advances in Water Resources, 104, 195-209. doi:10.1016/j.advwatres.2017.03.023

Van Delden, H., Seppelt, R., White, R., \& Jakeman, A. J. (2011). A methodology for the design and development of integrated models for policy support. Environmental Modelling \& Software, 26(3), 266-279. doi:10.1016/j.envsoft.2010.03.021

Van Delden, H., Stuczynski, T., Ciaian, P., Paracchini, M. L., Hurkens, J., Lopatka, A., Shi, Y.-e., Prieto, O. G., Calvo, S., van Vliet, J., \& Vanhout, R. (2010). Integrated assessment of agricultural policies with dynamic land use change modelling. Ecological Modelling, 221(18), 2153-2166. doi:10.1016/j.ecolmodel.2010.03.023

Van den Hurk, B., Tank, A. K., Lenderink, G., Van Ulden, A., Van Oldenborgh, G. J., Katsman, C., Van den Brink, H., Keller, F., Bessembinder, J., \& Burgers, G. (2007). New climate change scenarios for the Netherlands. Water Science and Technology, 56(4), 27-33.

Wada, Y., Bierkens, M. F. P., de Roo, A., Dirmeyer, P. A., Famiglietti, J. S., Hanasaki, N., Konar, M., Liu, J., Müller Schmied, H., Oki, T., Pokhrel, Y., Sivapalan, M., Troy, T. J., van Dijk, A. I. J. M., van Emmerik, T., Van Huijgevoort, M. H. J., Van Lanen, H. A. J., Vörösmarty, C. J., Wanders, N., \& Wheater, H. (2017). Human-water interface in hydrological modelling: current status and future directions. Hydrol. Earth Syst. Sci., 21(8), 4169-4193. doi:10.5194/hess-21-4169-2017

Wagner, P. D., Bhallamudi, S. M., Narasimhan, B., Kantakumar, L. N., Sudheer, K. P., Kumar, S., Schneider, K., \& Fiener, P. (2016). Dynamic integration of land use changes in a hydrologic assessment of a rapidly developing Indian catchment. Sci Total Environ, 539, 153-164. doi:10.1016/j.scitotenv.2015.08.148

Wagner, P. D., Bhallamudi, S. M., Narasimhan, B., Kumar, S., Fohrer, N., \& Fiener, P. (2017). Comparing the effects of dynamic versus static representations of land use change in hydrologic impact assessments. Environmental Modelling \& Software. doi:10.1016/j.envsoft.2017.06.023

Wagner, P. D., \& Waske, B. (2016). Importance of spatially distributed hydrologic variables for land use change modeling. Environmental Modelling \& Software, 83, 245-254. doi:10.1016/j.envsoft.2016.06.005

Walker, W., Haasnoot, M., \& Kwakkel, J. (2013). Adapt or Perish: A Review of Planning Approaches for Adaptation under Deep Uncertainty. Sustainability, 5(12), 955-979. doi:10.3390/su5030955

Wesselung, C. G., Karssenberg, D.-J., Burrough, P. A., \& Deursen, W. P. A. (1996). Integrating dynamic environmental models in GIS: The development of a Dynamic Modelling language. Transactions in GIS, 1(1), 40-48. doi:10.1111/j.14679671.1996.tb00032.x

Xu, D., Song, A., Tong, H., Ren, H., Hu, Y., \& Shao, Q. (2016). A spatial system dynamic model for regional desertification simulation - A case study of Ordos, China. Environmental Modelling \& Software, 83, 179-192. doi:10.1016/j.envsoft.2016.05.017

Zeff, H. B., Herman, J. D., Reed, P. M., \& Characklis, G. W. (2016). Cooperative drought adaptation: Integrating infrastructure development, conservation, and water transfers into adaptive policy pathways. Water Resources Research, 52(9), 7327-7346. doi:10.1002/2016WR018771

Zhang, J., Sun, J., Ma, B., \& Du, W. (2017). Assessing the ecological vulnerability of the upper reaches of the Minjiang River. PLoS ONE, 12(7), e0181825.

Zhang, L., Nan, Z., Yu, W., Zhao, Y., \& Xu, Y. (2018). Comparison of baseline period choices for separating climate and land use/land cover change impacts on watershed hydrology using distributed hydrological models. Science of the Total Environment, 622-623, 1016-1028. doi:10.1016/j.scitotenv.2017.12.055 